\title{
Recidivism of childhood cholesteatoma and surgical techniques: a meta-analysis study
}

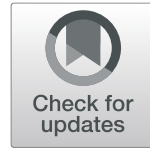

\author{
Yasser Shewel ${ }^{1 *}$ (D), Seddik Abdel Salam Tawfik', Abdulla A. L. Aaref ${ }^{1}$ and Noha Saleh ${ }^{2}$
}

\begin{abstract}
Background: There is a debate in the literature about surgical management of childhood cholesteatoma. We aimed to conduct a meta-analysis study about the recidivism of acquired cholesteatoma in children after two primary surgical procedures, namely canal wall up (CWU) and canal wall down (CWD) mastoidectomy.

Main body of the abstract: A Medline search of English language literature on PubMed and Cochrane Collaboration from their dates of inception until August 2019 was conducted using the following search terms: "pediatric or child and Cholesteatoma Surgery". Twenty-eight full-text papers fulfilled the selection criteria and were included in this meta-analysis

This analysis showed an odd risk of 1.72 for recidivism of childhood cholesteatoma in single-stage canal wall up procedure relative to canal wall down procedures. The $95 \%$ confidence interval (Cl) for the overall odds ratio was 1.27-2.34. The $P^{2}$ statistic was $37 \%$, representing low heterogeneity. Comparing the rate of recidivism before and after the year 2000 showed that there was still increased risk of recidivism in the canal wall up versus canal wall down mastoidectomy (the odds ratio was 1.87 and 1.57 respectively).

Short conclusion: Single-stage canal wall up mastoidectomy was significantly associated with a higher risk of cholesteatoma recidivism compared to canal wall down technique in children with acquired cholesteatoma

Keywords: Cholesteatoma, Recidivism, Children, Meta-analysis, Mastoidectomy
\end{abstract}

\section{Background}

Surgical management of cholesteatoma in children carries more challenges to otologist compared to the adults. Pediatric cholesteatoma is characterized by its aggressive behavior and a higher rate of recidivism. Increased incidence of upper respiratory tract infection and special features of Eustachian tube in children make them more vulnerable to a higher incidence of ear infection; in addition, good pneumatization of mastoids in children helps for more spread of disease compared with the sclerotic mastoid bones in adults. The pediatric cholesteatoma has more proliferative activity than that of the adult and may be another cause of aggressiveness of cholesteatoma in this age group [1-3].

\footnotetext{
* Correspondence: yshwel@yahoo.com

${ }^{1}$ Faculty of Medicine, Alexandria University, Champollion Street, El-Khartoum Square, El Azareeta Medical Campus, Alexandria 21131, Egypt

Full list of author information is available at the end of the article
}

Early intervention of pediatric cholesteatoma is crucial to avoid hearing loss that may have a great influence on the development of language and learning performance [4].

The aforementioned features specific to childhood cholesteatoma pose a serious challenge to otologist regarding surgical treatment of cholesteatoma.

The objectives of surgery for cholesteatoma in children are complete exenteration of the disease, prevention of recidivism, and improvement of hearing. Canal wall up (CWU) and canal wall down mastoidectomy (CWD) are the primary surgical approaches to accomplish these objectives [5].

The major surgical distinction between CWU and CWD procedures is whether or not to keep the canal wall intact. CWU mastoidectomy entails the removal of all mastoid air cells while preserving the integrity of the ear canal, while lowering the bony posterior canal wall 
up to the vertical part of the facial nerve is an essential surgical step in CWD mastoidectomy [6, 7].

In the CWU procedure, preserving the normal anatomy of the ear prevents the cavity problems that associated with CWD including frequent recurrent otorrhea, avoidance of exposure to water and water sport like swimming, shallow middle ear space with possible less favorable hearing results, vertigo because of exposure of lateral semicircular canal to cold air or water, prolonged postoperative recovery, a cosmetically unpleasing meatoplasty, and fitting of hearing aids is difficult $[8,9]$.

However, the main argument of the CWU procedure is the inability of this surgical technique of proper and adequate exposure of critical and hidden areas of the middle ear cleft such as sinus tympani, and epitympanic recess and therefore higher incidence of recidivism [10, 11]. To overcome the higher residual rate, many ear surgeons prefer to perform CWU surgery with a planned second look $[12,13]$. Some otologist reported higher recidivism with CWD technique [14, 15], yet others have stated similar recurrence rates regardless of the status of the canal wall $[13,16,17]$.

On reviewing the published data in literature, no meta-analysis was carried out about recidivism of childhood cholesteatoma following the two main surgical approaches; therefore, the aim of this study was to analyze available studies in literature and to carry meta-analysis about recidivism after single-stage canal wall up (CWU) and canal wall down (CWD) surgery in children with acquired cholesteatoma.

\section{Materials and methods Study design}

This meta-analysis was carried out in accordance with the guidelines of the Preferred Reporting Items for Systematic Reviews and Meta-Analyses (PRISMA). Different phases of this study were illustrated using the PRISMA flow diagram [18]. The ethical committee in our institution approved this research.

\section{Literature search}

A Medline review of English language literature on PubMed and Cochrane Collaboration from inception date until August 2019 was performed using the following search terms: "pediatric or child and Cholesteatoma Surgery".

Subsequent to the above-mentioned search terms, abstracts and titles were obtained and checked by two authors to identify the eligible articles for further analysis.

\section{Selection criteria}

To be included in the study, patients should be under 18 years old, original studies from peer-reviewed scientific journals were published in English, undergoing surgery for acquired cholesteatoma, rate of recidivism in both canal wall up and canal wall down approaches was analyzed in the same study, one-stage mastoid surgery, and follow-up time was nearly similar between both groups in same paper.

The following researches were excluded: animal, in vitro studies, review papers, case reports, studies on congenital cholesteatoma, studies without reference to original articles (e.g., only abstracts), and publications in which canal wall up surgery was undergone in two stages. In cases of using the same data in many publications by the same authors, the recently published study was included in the meta-analysis.

Full-text articles have been evaluated to see whether or not they meet the inclusion criteria. References of each study were checked manually to add more additional eligible articles.

\section{Data extraction}

All full texts were reviewed and analyzed by two authors independently to obtain the following data: author(s), year of publication, number of patients, demographic features of patients, number of ear surgeries, duration of follow-up for both approaches, and finally recidivism rates (including recurrent and residual cholesteatoma) for each technique.

\section{Study quality assessment}

The quality of included studies was checked using the Newcastle-Ottawa quality assessment Scale (NOS). The NOS has nine "stars," and the quality of the studies are graded into high (score > 6stars), moderate (4-6 stars), and low ( $\leq 3$ stars). The score of all studies was more than 6 stars and considered as good-quality studies.

\section{Statistical analysis}

All of the previously mentioned data were fed to Review Manager 5.3 (RevMan) program (Copenhagen: The Nordic Cochrane Centre, The Cochrane Collaboration 2014). The odds ratios and weight of each study were calculated with $95 \%$ confidence intervals (CI) using the Mantel-Haenszel method of metaanalysis. A forest plot was created showing the individual odds ratios and weights in addition to the pooled risk. The $I^{2}$ was calculated to determine the degree of heterogeneity which was classified into low $\left(I^{2}<0-50 \%\right)$, moderate $\left(I^{2}\right.$ between $\left.50-75 \%\right)$, or high $\left(I^{2}>75 \%\right)$.

We finally compare the recidivism of cholesteatoma in children before and after the year 2000 to determine any change in the rate of recidivism due to new innovation in imaging and surgical tools. 


\section{Results}

\section{Characteristics of the studies}

A flow diagram was created to show the search process, the initial detection, reasons for exclusion, and the final choice of the studies (Fig. 1).

After running the search terms "pediatric or child and Cholesteatoma Surgery", 2069 abstracts were obtained, and 255 abstracts were duplicated and excluded.

After the initial analysis of the abstracts, $1733 \mathrm{ab}$ stracts were excluded including 147 abstracts about congenital cholesteatoma; therefore, we reviewed 81 full-text articles to check for fulfilling the selection criteria.

Out of 81 full-text studies, 53 papers were excluded because of the following: insufficient data $(n=9)$, no distinguish between operative results in children versus adults $(n=1)$, using either CWU or CWD as only standard procedure $(n=23)$, no comparison between recidivism in CWU versus CWD procedure $(n=4)$, surgical outcome of congenital and acquired cholesteatoma was pooled together $(n=6)$ and older publication by same authors $(n=10)$. Only 28 studies fulfilled the selection criteria and were included in the meta-analysis.

The 28 studies included 3298 patients (3411 affected ears). On analyzing the previous 28 studies, 348 ears were excluded because they did not fulfill the inclusion criteria and had a congenital cholesteatoma, revision cases, or underwent surgical procedures other than CWU or CWD mastoidectomy; therefore, this study was carried out on 3063 ears with pediatric-acquired cholesteatoma. Canal wall up mastoidectomy was performed in 1905 ears, while 1158 ears underwent a canal wall down procedure.

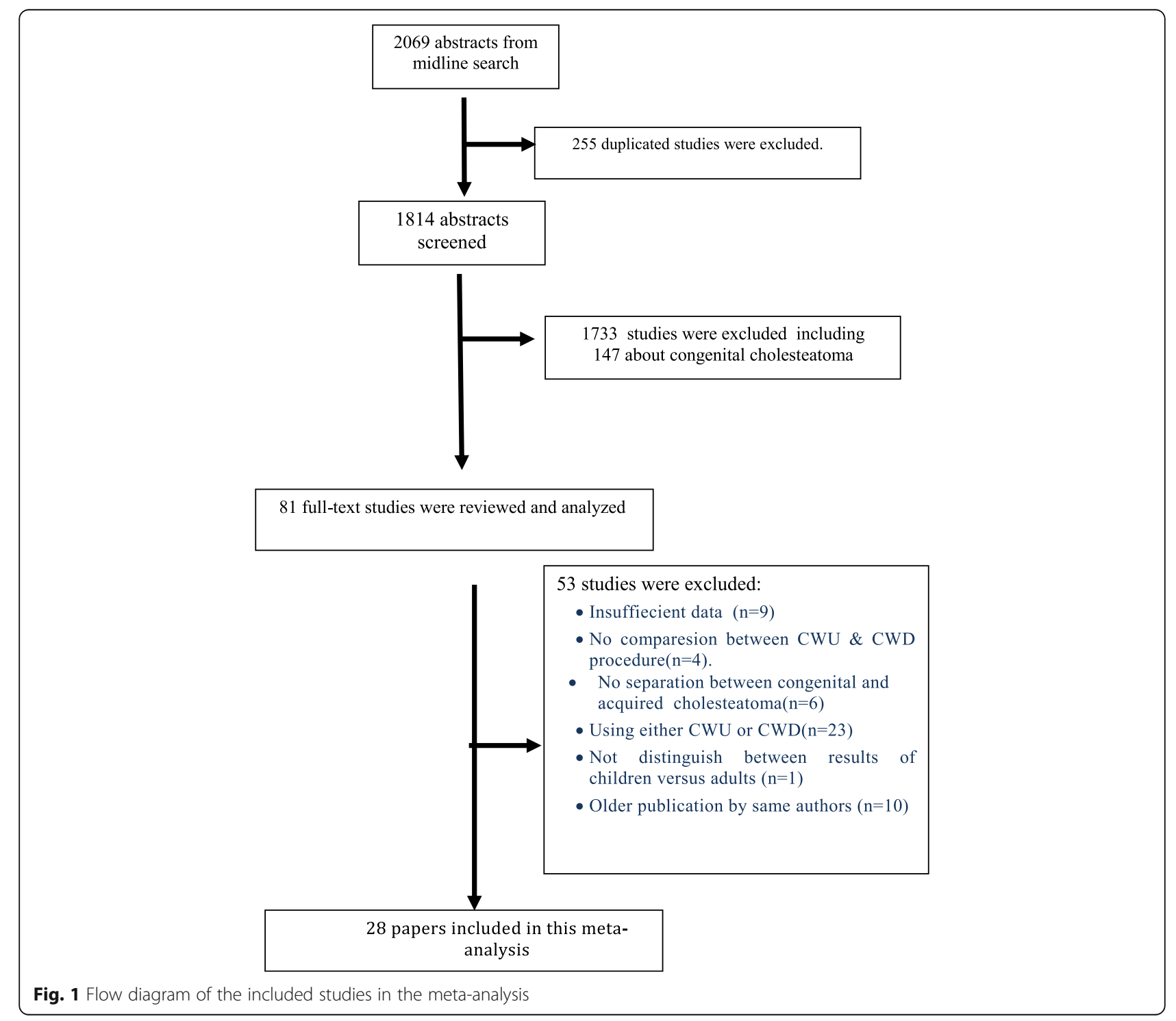




\section{Difference between included studies}

The studies varied widely in many aspects especially the demographic features of patients and mean duration of follow-up. Follow-up times among studies demonstrated significant variation, though, within each study, it was consistent. The follow-up periods ranged in from 1 to 10 years (Table 1 ).

The patient's number was variable from one study to another ranging from 18 to 493 patients. The mean age of patients varied from 8 to 13 years. These studies were conducted on 2061 (62.5\%) male and 1237 (37.5\%) female patients.

The rate of recidivism (recurrent and residual cholesteatoma) was highly variable from one study to another. Recidivism of cholesteatoma ranged from 5.26 to $80 \%$ in canal wall up approach while it ranged from 0 to $48 \%$ in canal wall down approach (Table 2).

The overall recidivism was 526/1905 (27.61\%) for CWU mastoidectomy, while it was $202 / 1158$ (17.44\%) for CWD mastoidectomy (Table 2).

\section{Meta-analysis}

For each study, the odds ratio (OR) and the 95\% confidence interval were demonstrated in Figs. 2 and 3. Based on the number of patients included in each study, the pooled odds ratio (OR) was weighted. The individual odds ratios varied from 0.53 to 9.33 and were weighted according to the number of patients included in this analysis to yield an odds ratio of 1.73 for recidivism of childhood cholesteatoma in canal wall up procedure relative to canal wall down procedures. The $95 \%$ confidence interval (CI) for the overall odds ratio was 1.272.34. The $I^{2}$ statistic was $37 \%$, representing low heterogeneity (Fig. 3).

There was no bias of publication as shown in the funnel plot (Fig. 4).

Comparing the results before and after the year 2000 showed that the aggregate odds ratio was 1.87 and 1.57 respectively for recidivism of cholesteatoma in canal wall up versus canal wall down mastoidectomy (Figs. 5 and 6).

\section{Discussion}

Surgical treatment of cholesteatoma is still a controversial issue, especially in the pediatric age group. The main surgical techniques commonly used for management of cholesteatoma are canal wall up (CWU) and canal wall down (CWD) mastoidectomy. Removal of the posterior and superior wall of the ear canal represents the major surgical difference between the previous approaches.

Many surgeons prefer canal wall up mastoidectomy, others favor performing canal wall down mastoidectomy, yet some authors advocated that the choice of surgical procedure should be tailored individually, considering many factors: the site and spread of the cholesteatoma, status of Eustachian tube function, the mastoid size and pneumatization, anatomical factor like low-lying dura of middle fossa and anterior position of sigmoid sinus, erosion of external auditory canal, presence of lateral canal fistula, ossicular involvement, and presence of complications [41, 42]. Patients with extensive cholesteatoma, Eustachian tube dysfunction, and contracted mastoids are candidates for canal wall down mastoidectomy [15].

Preoperative indications of CWD procedure include operating on an only hearing ear, poor anesthetic risk, or difficult follow-up [7].

Recidivism is one of the most crucial parameters that should be considered when comparing the outcomes of surgical approaches for the management of cholesteatoma.

Many ear surgeons believed that cholesteatoma recurrence is more common in CWD procedure than CWU procedure $[13,15,26,34]$.

On the other hand, other studies demonstrated that recidivism of cholesteatoma is more in CWU mastoidectomy than CWD mastoidectomy [7, 19-25, 28, 29].

In this meta-analysis, we investigated the percentage of recidivism (recurrent and/or residual cholesteatoma) in two main surgical approaches (CWU and CWD mastoidectomy) for treatment of the acquired type of childhood cholesteatoma.

Data from literature included in our meta-analysis study showed a variable range of recidivism of cholesteatoma for canal wall up and canal wall down groups. For canal wall up, the lowest recorded recurrence rate was $5.26 \%$ and the highest was $80 \%$ with a mean of $27.61 \%$ while for canal wall down the lowest recurrence rate was $0 \%$ and the highest was $48 \%$ with a mean of $17.44 \%$.

This study showed a significant aggregate odds ratio of 1.73 for recidivism which means that children who underwent the canal wall up approach are 1.73 times to have residual and/or recurrent cholesteatoma compared to children who received the canal wall down approach.

We compared the result of canal wall mastoidectomy versus canal wall down mastoidectomy before and after the year of 2000 to show if the advances of imaging or surgical technology have effects on the recidivism rate. The meta-analysis showed that the risk of recidivism was still higher in canal wall up than canal wall down mastoidectomy before and after the year 2000 (the aggregate odds ratio was 1.87 before year 2000 versus 1.57 after the year 2000).

The higher rate of recidivism dictates second-look surgery after canal wall up mastoidectomy. Second-look surgery is not without its drawbacks, including the financial burden of the second surgery on patient and 


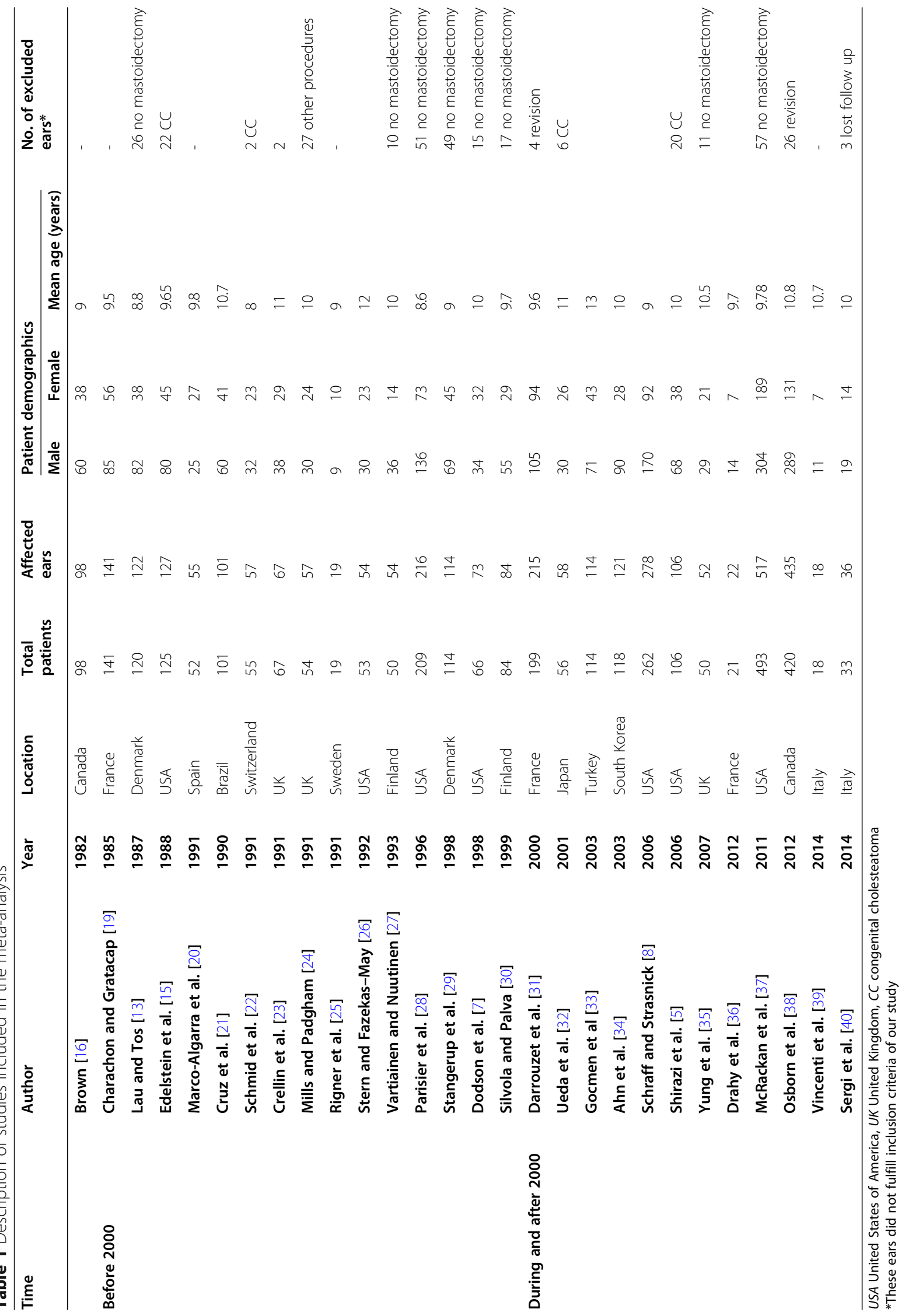




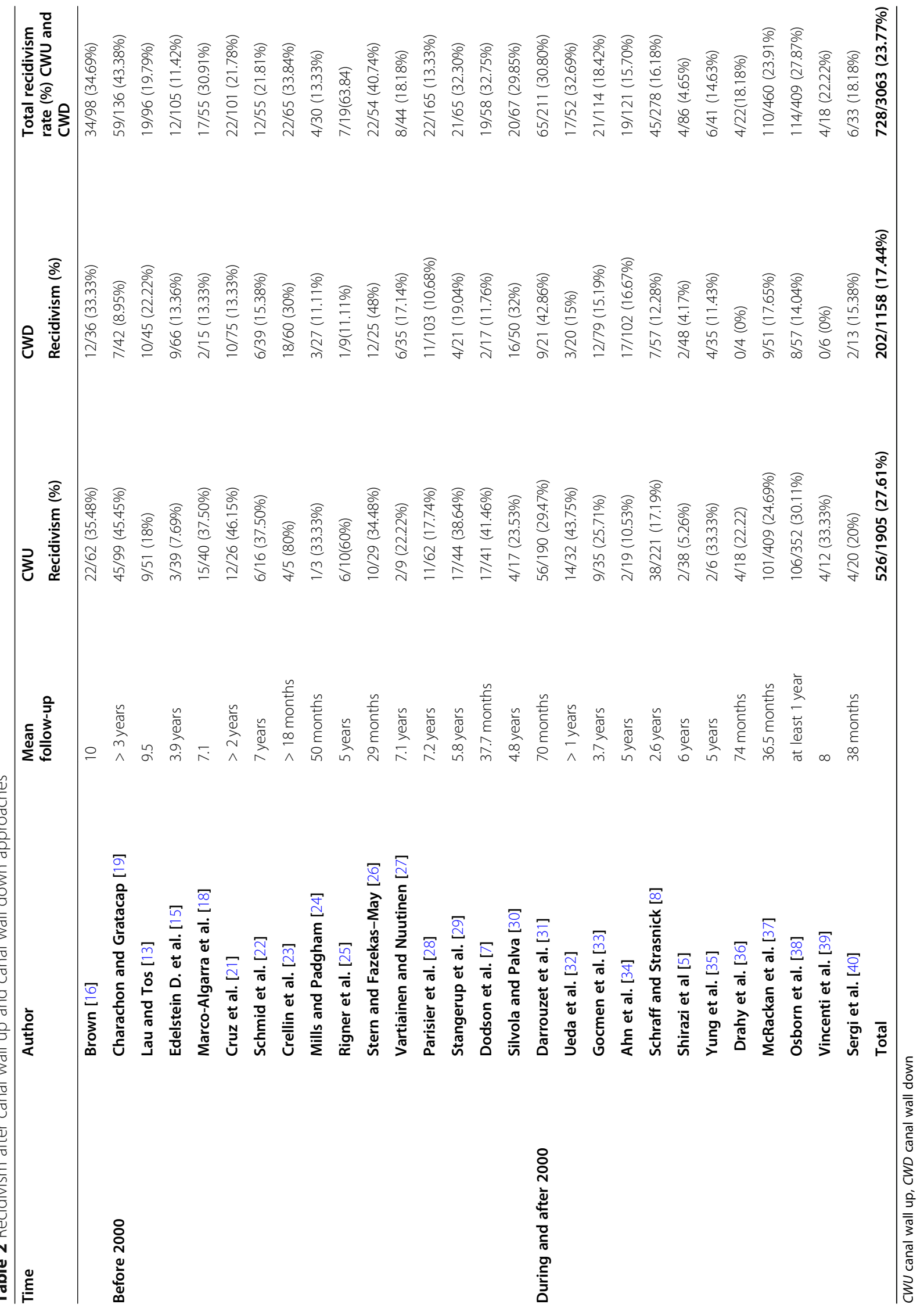




\begin{tabular}{|c|c|c|c|c|c|c|c|c|c|c|c|}
\hline \multirow[b]{2}{*}{ Study or Subgroup } & \multicolumn{2}{|c|}{ CWU mastoidectomy } & \multicolumn{2}{|c|}{ CWD mastoidectomy } & \multicolumn{3}{|c|}{ Odds Ratio } & \multirow{2}{*}{\multicolumn{4}{|c|}{$\begin{array}{c}\text { Odds Ratio } \\
\mathrm{M}-\mathrm{H}, \text { Random, } 95 \% \mathrm{Cl}\end{array}$}} \\
\hline & Events & Total & Events & Total & Weight & $\mathrm{M}-\mathrm{H}$, Random, $95 \% \mathrm{Cl}$ & Year & & & & \\
\hline Brown 1982 & 22 & 62 & 12 & 36 & $5.7 \%$ & $1.10[0.46,2.62]$ & 1982 & & & & \\
\hline Charachon et al. 1985 & 45 & 99 & 7 & 42 & $5.5 \%$ & $4.17[1.69,10.28]$ & 1985 & & & & \\
\hline Lau and Tos 1987 & 9 & 51 & 10 & 45 & $4.9 \%$ & $0.75[0.27,2.05]$ & 1987 & & & & \\
\hline Edelstein et al. 1988 & 3 & 39 & 9 & 66 & $3.4 \%$ & $0.53[0.13,2.08]$ & 1988 & & & & \\
\hline Cruz et al. 1990 & 12 & 26 & 10 & 75 & $4.9 \%$ & $5.57[2.01,15.43]$ & 1990 & & & & \\
\hline Marco-Algarra et al 1991 & 15 & 40 & 2 & 15 & $2.7 \%$ & $3.90[0.77,19.72]$ & 1991 & & & & \\
\hline Mills and Padgham 1991 & 1 & 3 & 3 & 27 & $1.2 \%$ & $4.00[0.27,58.56]$ & 1991 & & & & \\
\hline Crellin et al. 1991 & 4 & 5 & 18 & 60 & $1.6 \%$ & $9.33[0.97,89.42]$ & 1991 & & & & \\
\hline Schmid et al. 1991 & 6 & 16 & 6 & 39 & $3.5 \%$ & $3.30[0.87,12.53]$ & 1991 & & & & \\
\hline Rigner et al. (1991 & 6 & 10 & 1 & 9 & $1.4 \%$ & $12.00[1.05,136.79]$ & 1991 & & & & \\
\hline Stern and Fazekas -May 1992 & 10 & 29 & 12 & 25 & $4.5 \%$ & $0.57[0.19,1.71]$ & 1992 & & & & \\
\hline Vartiainen 1993 & 2 & 9 & 6 & 35 & $2.3 \%$ & $1.38[0.23,8.36]$ & 1993 & & & & \\
\hline Parisier et al. 1996 & 11 & 62 & 11 & 103 & $5.5 \%$ & $1.80[0.73,4.45]$ & 1996 & & & & \\
\hline Dodson et al. 1998 & 17 & 41 & 2 & 17 & $2.7 \%$ & $5.31[1.07,26.34]$ & 1998 & & & & \\
\hline Stangerup et al. 1998 & 17 & 44 & 4 & 21 & $3.8 \%$ & $2.68[0.77,9.31]$ & 1998 & & & & \\
\hline Silvola and Palva1999 & 4 & 17 & 16 & 50 & $3.8 \%$ & $0.65[0.18,2.32]$ & 1999 & & & & \\
\hline Darrouzet et al. 2000 & 56 & 190 & 9 & 21 & $5.4 \%$ & $0.56[0.22,1.40]$ & 2000 & & & - & \\
\hline Ueda et al. 2001 & 14 & 32 & 3 & 20 & $3.2 \%$ & $4.41[1.07,18.09]$ & 2001 & & & & \\
\hline Gocmen et al. 2003 & 9 & 35 & 12 & 79 & $5.1 \%$ & $1.93[0.73,5.13]$ & 2003 & & & & \\
\hline Ahn et al. 2003 & 2 & 19 & 17 & 102 & $2.8 \%$ & $0.59[0.12,2.79]$ & 2003 & & & & \\
\hline Schraff 2005 & 38 & 221 & 7 & 57 & $5.7 \%$ & $1.48[0.62,3.52]$ & 2005 & & & & \\
\hline Shirazi et al .2006 & 2 & 38 & 2 & 48 & $1.9 \%$ & $1.28[0.17,9.52]$ & 2006 & & & & \\
\hline Yung et al. 2007 & 2 & 6 & 4 & 35 & $1.9 \%$ & $3.88[0.53,28.39]$ & 2007 & & & & \\
\hline Drahy et al 2010 & 4 & 18 & 0 & 4 & $0.9 \%$ & $2.79[0.12,62.45]$ & 2010 & & & & \\
\hline Theodore et al. 2011 & 101 & 409 & 9 & 51 & $6.4 \%$ & $1.53[0.72,3.25]$ & 2011 & & & & \\
\hline Osborn et al. 2012 & 106 & 352 & 8 & 57 & $6.3 \%$ & $2.64[1.21,5.76]$ & 2012 & & & & \\
\hline Vincenti et al. 2014 & 4 & 12 & 0 & 6 & $0.9 \%$ & $6.88[0.31,152.02]$ & 2014 & & & & \\
\hline Sergi et al. 2014 & 4 & 20 & 2 & 13 & $2.1 \%$ & $1.38[0.21,8.86]$ & 2014 & & & & \\
\hline Total $(95 \% \mathrm{Cl})$ & & 1905 & & 1158 & $100.0 \%$ & $1.80[1.32,2.44]$ & & & & & \\
\hline Total events & 526 & & 202 & & & & & & & & \\
\hline $\begin{array}{l}\text { Heterogeneity: } \mathrm{Tau}^{2}=0.23 ; \mathrm{Chi}^{2} \\
\text { Test for overall effect: } Z=3.76(\mathrm{~F}\end{array}$ & $\begin{array}{l}43.15, \mathrm{df}=27 \\
=0.0002)\end{array}$ & $=0.03) ; 1$ & $1^{2}=37 \%$ & & & & & 0.01 & 0.1 & 10 & $\overrightarrow{100}$ \\
\hline
\end{tabular}

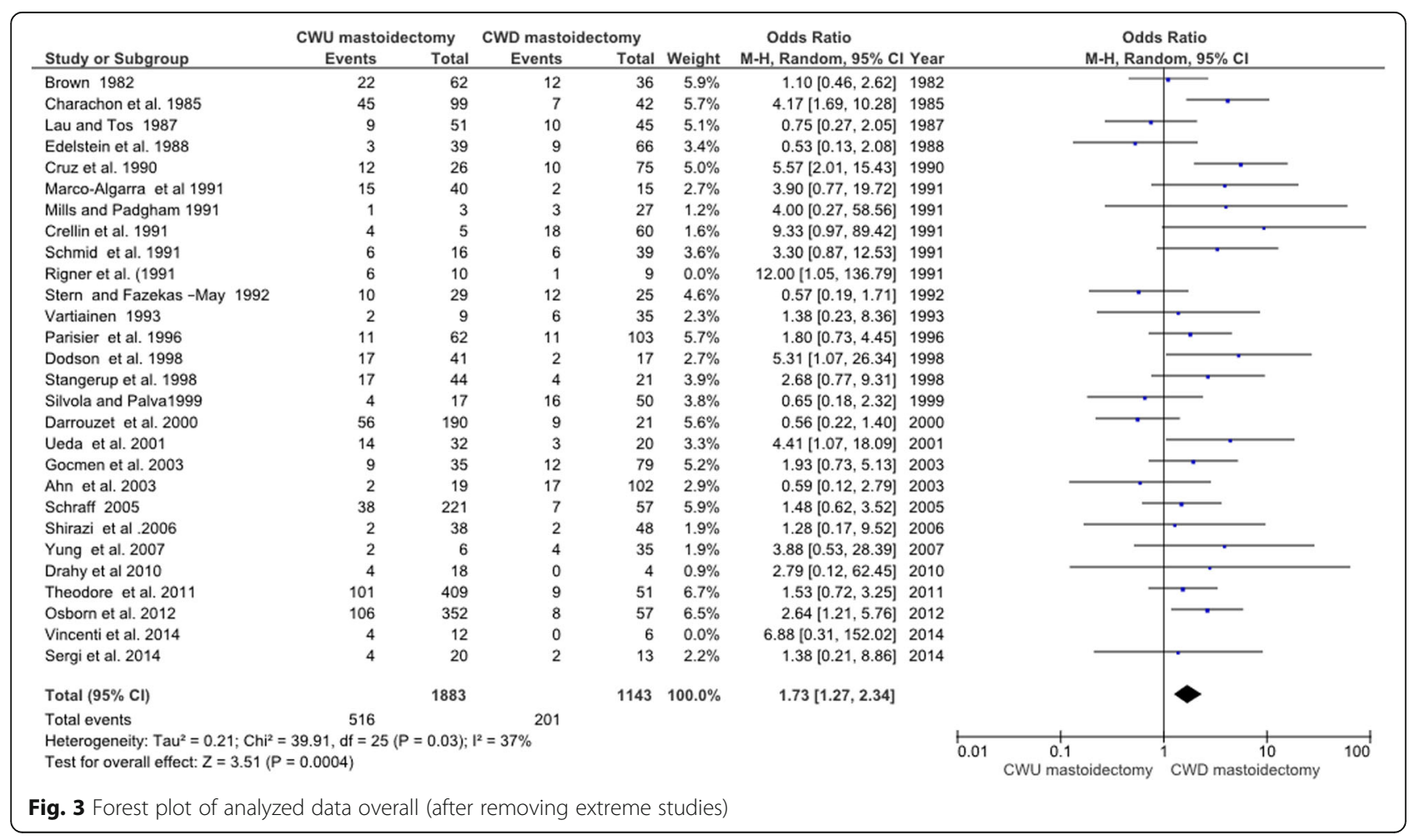




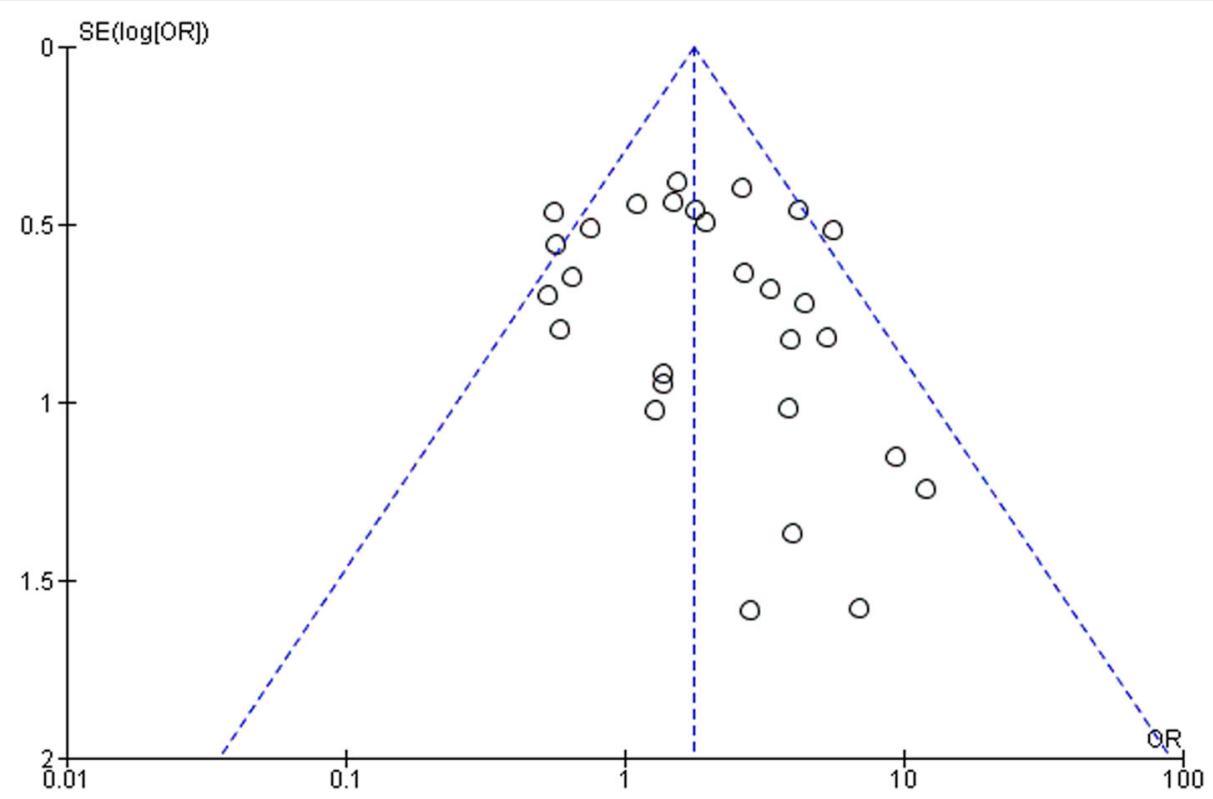

Fig. 4 Funnel plot for publication bias

institution, risk of anesthesia, and challenges related to altered anatomical landmarks due to previous surgery [43].

Different surgical techniques have been performed to overcome the disadvantages of CWU (high recidivism rates) and CWD (cavity problems) mastoidectomy including reconstruction of canal using cartilage and cortical bone [4] and using endoscopes for superior exposure of hidden spots in middle ear especially sinus tympani which represents most common site of recidivism during cholesteatoma surgery [44].

This meta-analysis showed that CWU mastoidectomy is a risk factor for recidivism; however, other researchers stated that there are other risk factors for recurrence of cholesteatoma rather than the surgical technique. The

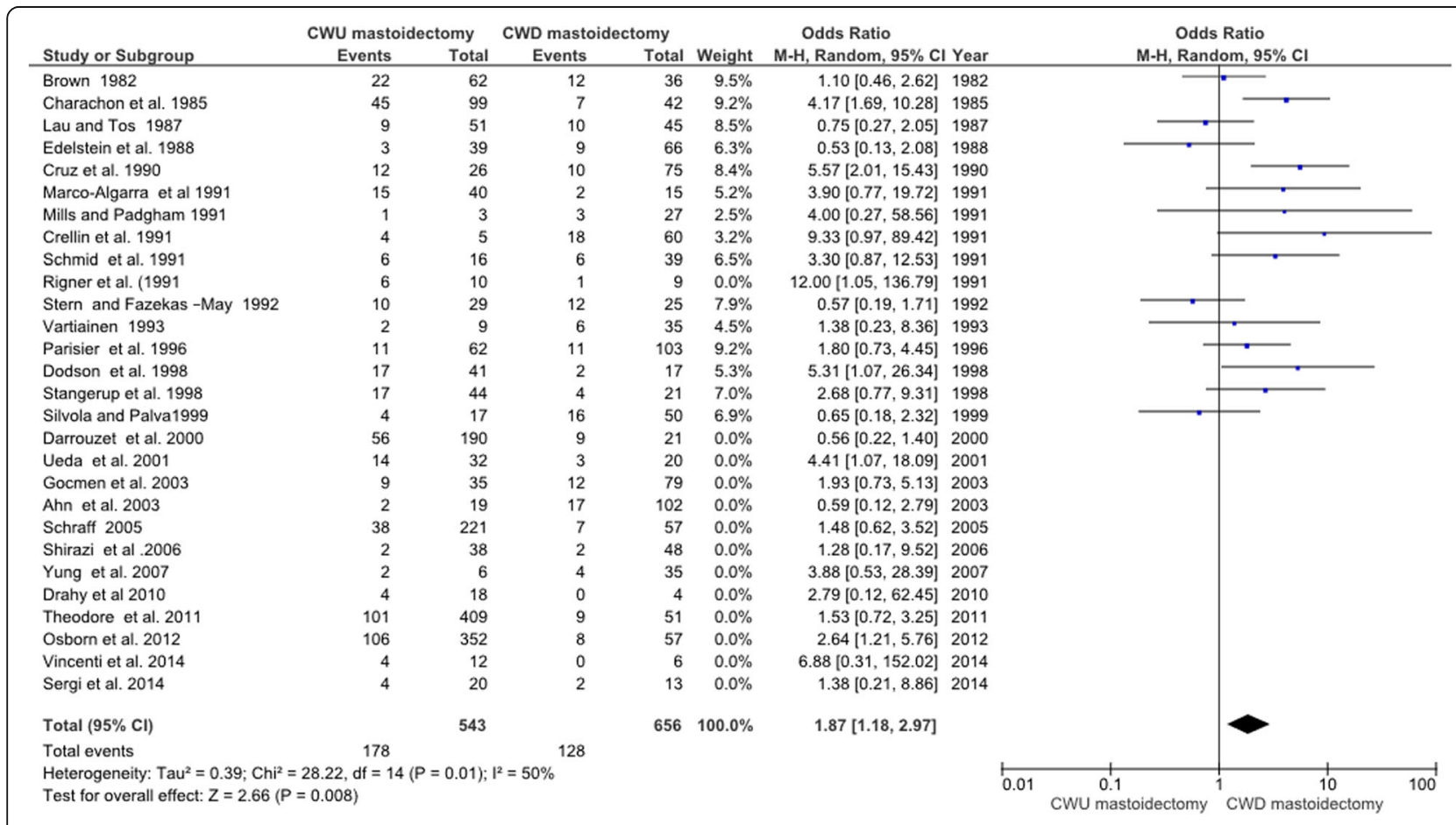

Fig. 5 Forest plot of analyzed data before the year 2000 


\begin{tabular}{|c|c|c|c|c|c|c|c|c|c|c|c|}
\hline \multirow[b]{2}{*}{ Study or Subgroup } & \multicolumn{2}{|c|}{ CWU mastoidectomy } & \multicolumn{2}{|c|}{ CWD mastoidectomy } & \multicolumn{3}{|c|}{ Odds Ratio } & \multirow{2}{*}{\multicolumn{4}{|c|}{$\begin{array}{c}\text { Odds Ratio } \\
\mathrm{M}-\mathrm{H}, \text { Random, } 95 \% \mathrm{Cl}\end{array}$}} \\
\hline & Events & Total & Events & Total & Weight & $\mathrm{M}-\mathrm{H}$, Random, $95 \% \mathrm{Cl}$ & 1 Year & & & & \\
\hline Brown 1982 & 22 & 62 & 12 & 36 & $0.0 \%$ & $1.10[0.46,2.62]$ & 1982 & & & & \\
\hline Charachon et al. 1985 & 45 & 99 & 7 & 42 & $0.0 \%$ & $4.17[1.69,10.28]$ & 1985 & & & & \\
\hline Lau and Tos 1987 & 9 & 51 & 10 & 45 & $0.0 \%$ & $0.75[0.27,2.05]$ & 1987 & & & & \\
\hline Edelstein et al. 1988 & 3 & 39 & 9 & 66 & $0.0 \%$ & $0.53[0.13,2.08]$ & 1988 & & & & \\
\hline Cruz et al. 1990 & 12 & 26 & 10 & 75 & $0.0 \%$ & $5.57[2.01,15.43]$ & 1990 & & & & \\
\hline Marco-Algarra et al 1991 & 15 & 40 & 2 & 15 & $0.0 \%$ & $3.90[0.77,19.72]$ & 1991 & & & & \\
\hline Mills and Padgham 1991 & 1 & 3 & 3 & 27 & $0.0 \%$ & $4.00[0.27,58.56]$ & 1991 & & & & \\
\hline Crellin et al. 1991 & 4 & 5 & 18 & 60 & $0.0 \%$ & $9.33[0.97,89.42]$ & 1991 & & & & \\
\hline Schmid et al. 1991 & 6 & 16 & 6 & 39 & $0.0 \%$ & $3.30[0.87,12.53]$ & 1991 & & & & \\
\hline Rigner et al. (1991 & 6 & 10 & 1 & 9 & $0.0 \%$ & $12.00[1.05,136.79]$ & 1991 & & & & \\
\hline Stern and Fazekas -May 1992 & 10 & 29 & 12 & 25 & $0.0 \%$ & $0.57[0.19,1.71]$ & 1992 & & & & \\
\hline Vartiainen 1993 & 2 & 9 & 6 & 35 & $0.0 \%$ & $1.38[0.23,8.36]$ & 1993 & & & & \\
\hline Parisier et al. 1996 & 11 & 62 & 11 & 103 & $0.0 \%$ & $1.80[0.73,4.45]$ & 1996 & & & & \\
\hline Dodson et al. 1998 & 17 & 41 & 2 & 17 & $0.0 \%$ & $5.31[1.07,26.34]$ & 1998 & & & & \\
\hline Stangerup et al. 1998 & 17 & 44 & 4 & 21 & $0.0 \%$ & $2.68[0.77,9.31]$ & 1998 & & & & \\
\hline Silvola and Palva1999 & 4 & 17 & 16 & 50 & $0.0 \%$ & $0.65[0.18,2.32]$ & 1999 & & & & \\
\hline Darrouzet et al. 2000 & 56 & 190 & 9 & 21 & $13.5 \%$ & $0.56[0.22,1.40]$ & 2000 & & & - & \\
\hline Ueda et al. 2001 & 14 & 32 & 3 & 20 & $6.4 \%$ & $4.41[1.07,18.09]$ & 2001 & & & & \\
\hline Gocmen et al. 2003 & 9 & 35 & 12 & 79 & $12.2 \%$ & $1.93[0.73,5.13]$ & 2003 & & & & \\
\hline Ahn et al. 2003 & 2 & 19 & 17 & 102 & $5.3 \%$ & $0.59[0.12,2.79]$ & 2003 & & & & \\
\hline Schraff 2005 & 38 & 221 & 7 & 57 & $14.9 \%$ & $1.48[0.62,3.52]$ & 2005 & & & - & \\
\hline Shirazi et al .2006 & 2 & 38 & 2 & 48 & $3.3 \%$ & $1.28[0.17,9.52]$ & 2006 & & & & \\
\hline Yung et al. 2007 & 2 & 6 & 4 & 35 & $3.3 \%$ & $3.88[0.53,28.39]$ & 2007 & & & & \\
\hline Drahy et al 2010 & 4 & 18 & 0 & 4 & $1.4 \%$ & $2.79[0.12,62.45]$ & 2010 & & & & \\
\hline Theodore et al. 2011 & 101 & 409 & 9 & 51 & $18.5 \%$ & $1.53[0.72,3.25]$ & 2011 & & & 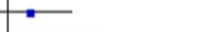 & \\
\hline Osborn et al. 2012 & 106 & 352 & 8 & 57 & $17.5 \%$ & $2.64[1.21,5.76]$ & 2012 & & & & \\
\hline Vincenti et al. 2014 & 4 & 12 & 0 & 6 & $0.0 \%$ & $6.88[0.31,152.02]$ & 2014 & & & & \\
\hline Sergi et al. 2014 & 4 & 20 & 2 & 13 & $3.8 \%$ & $1.38[0.21,8.86]$ & 2014 & & & & \\
\hline Total $(95 \% \mathrm{Cl})$ & & 1340 & & 487 & $100.0 \%$ & $1.57[1.09,2.28]$ & & & & & \\
\hline Total events & 338 & & 73 & & & & & & & & \\
\hline $\begin{array}{l}\text { Heterogeneity: } \mathrm{Tau}^{2}=0.05 ; \mathrm{Chi}^{2} \\
\text { Test for overall effect: } Z=2.40(P\end{array}$ & $\begin{array}{l}11.36, \mathrm{df}=10 \\
=0.02)\end{array}$ & $=0.33) ; 1$ & $\left.\right|^{2}=12 \%$ & & & & & 0.01 & $\begin{array}{c}0.1 \\
\text { CWU mastoidectomy }\end{array}$ & ${ }^{1} \frac{10}{\text { CWD mastoidectomy }}$ & $\underset{100}{1}$ \\
\hline
\end{tabular}

ossicular erosion was reported to be linked with cholesteatoma recidivism [45].

Involvement of the facial recess or the sinus tympani by cholesteatoma was considered one of the most common causes of failure of the CWU approach [46].

Roger et al. found that extension of cholesteatoma to posterior mesotympanum, interruption of the ossicular chain after cholesteatoma excision, surgeon experience, and incomplete excision of cholesteatoma are associated with recidivism of cholesteatoma [17].

The value of this analysis lies in the data consistency. It is clear from forest plot that recidivism was lower in canal wall down mastoidectomy in 22 out of the 28 studies while only 6 studies favor the canal wall up approach due to lower recidivism compared to canal wall up technique.

One of the critiques in this review was the variability of postoperative follow-up time from one study to another. Many studies reported that longer postoperative follow-up was associated with higher rates of recidivism $[13,47,48]$. However, the postoperative follow-up was the same within each study which is essential to compare the rate of the recidivism between the two surgical approaches.

Another point of criticism is the detection method of the recidivism in the postoperative follow-up. Many authors detected recurrent disease by otomicroscopy; however, the majority does not determine the exact methods of detection of recurrence. Others detected recurrence during second-stage surgery especially in canal wall up mastoidectomy which commonly revised months to years after primary surgery. Therefore, it is essential to standardize our method of detection of recurrent disease. The diffuse-weighted MRI may be used in postoperative follow-up for detection recurrent and residual disease, reducing the rate of second-look surgery. A recent meta-analysis study showed that diffusion-weighted MRI is highly sensitive and specific for detection of recidivism after cholesteatoma surgery as MRI can detect cholesteatoma as small as $3 \mathrm{~mm}[49,50]$.

Despite enormous studies on cholesteatoma, we faced many difficulties during the analysis of data including reporting of recidivism rate as recurrent and residual rates are often used interchangeably. Another major problem related to inconsistencies among reports regarding the staging of cholesteatoma and variation in the description of surgical techniques and their surgical modifications, which can impede the comparison of the outcomes.

\section{Conclusion}

This meta-analysis showed that canal wall up mastoidectomy had a higher risk of recidivism compared to canal down technique in children with acquired cholesteatoma

Abbreviations

PRISMA: Preferred Reporting Items for Systematic Reviews and MetaAnalyses; COM: Chronic otitis media; CWU: Canal wall up; CWD: Canal wall down 


\section{Acknowledgements}

Not applicable

\section{Authors' contributions}

All authors have read and approved the manuscript. YS: contributions to the conception and design of the work; the acquisition, analysis, and interpretation of data; drafted the work, revised it, approved the submitted version, and agreed to be personally accountable for the author's own contributions and to ensure that questions related to the accuracy or integrity of any part of the work, even ones in which the author was not personally involved, are appropriately investigated, resolved, and the resolution documented in the literature. ST: contributions to the conception, substantively revised it, and approved the submitted version, and agreed to be personally accountable for the author's own contributions and to ensure that questions related to the accuracy or integrity of any part of the work, even ones in which the author was not personally involved, are appropriately investigated, resolved, and the resolution documented in the literature. AA: the acquisition, analysis, and interpretation of data; drafted the work, revised it, and approved the submitted version and agreed to be personally accountable for the author's own contributions and to ensure that questions related to the accuracy or integrity of any part of the work, even ones in which the author was not personally involved, are appropriately investigated, resolved, and the resolution documented in the literature. NS: analysis, interpretation of data; revised it and approved the submitted version and agreed to be personally accountable for the author's own contributions and to ensure that questions related to the accuracy or integrity of any part of the work, even ones in which the author was not personally involved, are appropriately investigated, resolved, and the resolution documented in the literature.

\section{Funding}

None

\section{Availability of data and materials}

All data generated or analyzed during this study are included in this published article.

\section{Ethics approval and consent to participate}

The ethical committee of Faculty of Medicine, Alexandria University, Egypt, approved this work (ethical number 00007555). Consent to participate is not applicable.

\section{Consent for publication}

Not applicable

\section{Competing interests}

The authors declare that they have no competing interests.

\section{Author details}

${ }^{1}$ Faculty of Medicine, Alexandria University, Champollion Street, El-Khartoum Square, El Azareeta Medical Campus, Alexandria 21131, Egypt. ${ }^{2}$ High Institute of Public Health, Alexandria University, Alexandria, Egypt.

Received: 12 March 2020 Accepted: 29 September 2020 Published online: 14 October 2020

\section{References}

1. Dornhoffer JL, Friedman AB, Gluth MB (2013) Management of acquired cholesteatoma in the pediatric population. Current opinion in otolaryngology \& head and neck surgery 21(5):440-445. https://doi.org/10. 1097/MOO.0b013e32836464bd

2. Dornelles Cde C, da Costa SS, Meurer L, Rosito LP, da Silva AR, Alves SL (2009) Comparison of acquired cholesteatoma between pediatric and adult patients. European archives of oto-rhino-laryngology : official journal of the European Federation of Oto-Rhino-Laryngological Societies 266(10):15531561. https://doi.org/10.1007/s00405-009-0957-0

3. Quaranta A, Resta L, Santangelo A (1986) Otomastoid cholesteatoma in children: histopathological findings. International journal of pediatric otorhinolaryngology 12(2):121-126

4. Kuo CL, Shiao AS, Liao WH, Ho CY, Lien CF (2012) Can long-term hearing preservation be expected in children following cholesteatoma surgery?
Results from a 14-year-long study of atticotomy-limited mastoidectomy with cartilage reconstruction. Audiology \& neuro-otology 17(6):386-394 https://doi.org/10.1159/000341985

5. Shirazi MA, Muzaffar K, Leonetti JP, Marzo S (2006) Surgical treatment of pediatric cholesteatomas. The Laryngoscope 116(9):1603-1607. https://doi. org/10.1097/01.mlg.0000233248.03276.9b

6. Nikolopoulos TP, Gerbesiotis P (2009) Surgical management of cholesteatoma: the two main options and the third way--atticotomy/limited mastoidectomy. International journal of pediatric otorhinolaryngology 73(9): 1222-1227. https://doi.org/10.1016/j.ijporl.2009.05.010

7. Dodson EE, Hashisaki GT, Hobgood TC, Lambert PR (1998) Intact canal wall mastoidectomy with tympanoplasty for cholesteatoma in children. The Laryngoscope 108(7):977-983

8. Schraff SA, Strasnick B (2006) Pediatric cholesteatoma: a retrospective review. International journal of pediatric otorhinolaryngology 70(3):385-393. https://doi.org/10.1016/j.jporl.2005.10.006

9. Tomlin J, Chang D, McCutcheon B, Harris J (2013) Surgical technique and recurrence in cholesteatoma: a meta-analysis. Audiology \& neuro-otology 18(3):135-142. https://doi.org/10.1159/000346140

10. Uzun C, Kutoglu T (2007) Assessment of visualization of structures in the middle ear via Tos modified canal wall-up mastoidectomy versus classic canal wall-up and canal wall-down mastoidectomies. International journal of pediatric otorhinolaryngology 71(6):851-856. https://doi.org/10.1016/j. ijporl.2007.02.004

11. Hulka GF, McElveen JT Jr (1998) A randomized, blinded study of canal wall up versus canal wall down mastoidectomy determining the differences in viewing middle ear anatomy and pathology. The American journal of otology 19(5):574-578

12. Sanna M, Zini C, Gamoletti R, Delogu P, Scandellari R, Russo A, Taibah A (1987) Prevention of recurrent cholesteatoma in closed tympanoplasty. The Annals of otology, rhinology, and laryngology 96(3 Pt 1):273-275. https:// doi.org/10.1177/000348948709600307

13. Lau T, Tos M (1987) Cholesteatoma in children: recurrence related to observation period. American journal of otolaryngology 8(6):364-375

14. Charachon R (1988) Surgery of cholesteatoma in children. The Journal of laryngology and otology 102(8):680-684. https://doi.org/10.1017/ s0022215100106140

15. Edelstein DR, Parisier SC, Ahuja GS, Juarbe C, Chute P, Wenig S, Kaye SM (1988) Cholesteatoma in the pediatric age group. The Annals of otology, rhinology, and laryngology 97(1):23-29. https://doi.org/10.1177/ 000348948809700105

16. Brown JS (1982) A ten year statistical follow-up of 1142 consecutive cases of cholesteatoma: the closed vs. the open technique. The Laryngoscope 92(4): 390-396

17. Roger G, Denoyelle F, Chauvin P, Schlegel-Stuhl N, Garabedian EN (1997) Predictive risk factors of residual cholesteatoma in children: a study of 256 cases. The American journal of otology 18(5):550-558

18. Liberati A, Altman DG, Tetzlaff J, Mulrow C, Gotzsche PC, loannidis JP, Clarke M, Devereaux PJ, Kleijnen J, Moher D (2009) The PRISMA statement for reporting systematic reviews and meta-analyses of studies that evaluate healthcare interventions: explanation and elaboration. BMJ 339:b2700. https://doi.org/10.1136/bmj.b2700

19. Charachon R, Gratacap B (1985) The surgical treatment of cholesteatoma in children. Clinical otolaryngology and allied sciences 10(4):177-184

20. Marco-Algarra J, Gimenez F, Mallea I, Armengot M, de la Fuente L (1991) Cholesteatoma in children: results in open versus closed techniques. The Journal of laryngology and otology 105(10):820-824. https://doi.org/10. 1017/s0022215100117438

21. Cruz OL, Takeuti M, Caldas Neto S, Miniti A (1990) Clinical and surgical aspects of cholesteatomas in children. Ear, nose, \& throat journal 69 (8):530, 535-536

22. Schmid H, Dort JC, Fisch U (1991) Long-term results of treatment for children's cholesteatoma. The American journal of otology 12(2):83-87

23. Crellin RP, Wilson JA, Cowan DL (1991) Mastoid surgery in childhood. Clinical otolaryngology and allied sciences 16(1):39-42

24. Mills RP, Padgham ND (1991) Management of childhood cholesteatoma. The Journal of laryngology and otology 105(5):343-345. https://doi.org/10. 1017/s0022215100115944

25. Rigner P, Renvall U, Tjellstrom A (1991) Late results after cholesteatoma surgery in early childhood. International journal of pediatric otorhinolaryngology 22(3):213-218 
26. Stern SJ, Fazekas-May M (1992) Cholesteatoma in the pediatric population: prognostic indicators for surgical decision making. The Laryngoscope 102(12 Pt 1):1349-1352. https://doi.org/10.1288/00005537-199212000-00007

27. Vartiainen E, Nuutinen J (1992) Long-term results of surgery for childhood cholesteatoma. International journal of pediatric otorhinolaryngology 24(3):201-208

28. Parisier SC, Hanson MB, Han JC, Cohen AJ, Selkin BA (1996) Pediatric cholesteatoma: an individualized, single-stage approach. Otolaryngology-head and neck surgery : official journal of American Academy of Otolaryngology-Head and Neck Surgery 115(1):107-114. https://doi.org/10 1016/S0194-5998(96)70145-6

29. Stangerup SE, Drozdziewicz D, Tos M, Trabalzini F (1998) Surgery for acquired cholesteatoma in children: long-term results and recurrence of cholesteatoma. The Journal of laryngology and otology 112(8):742-749. https://doi.org/10.1017/s0022215100141581

30. Silvola J, Palva T (1999) Pediatric one-stage cholesteatoma surgery: long term results. International journal of pediatric otorhinolaryngology 49(Suppl 1):S87-S90

31. Darrouzet V, Duclos JY, Portmann D, Bebear JP (2000) Preference for the closed technique in the management of cholesteatoma of the middle ear in children: a retrospective study of 215 consecutive patients treated over 10 years. The American journal of otology 21(4):474-481

32. Ueda H, Nakashima T, Nakata S (2001) Surgical strategy for cholesteatoma in children. Auris, nasus, larynx 28(2):125-129

33. Gocmen H, Kilic R, Ozdek A, Kizilkaya Z, Safak MA, Samim E (2003) Surgical treatment of cholesteatoma in children. International journal of pediatric otorhinolaryngology 67(8):867-872

34. Ahn SH, Oh SH, Chang SO, Kim CS (2003) Prognostic factors of recidivism in pediatric cholesteatoma surgery. International journal of pediatric otorhinolaryngology 67(12):1325-1330

35. Yung M, Jacobsen NL, Vowler SL (2007) A 5-year observational study of the outcome in pediatric cholesteatoma surgery. Otology \& neurotology : official publication of the American Otological Society, American Neurotology Society [and] European Academy of Otology and Neurotology 28(8):1038-1040. https://doi.org/10.1097/mao.0b013e318159e799

36. Drahy A, De Barros A, Lerosey Y, Choussy O, Dehesdin D, Marie JP (2012) Acquired cholesteatoma in children: strategies and medium-term results. European annals of otorhinolaryngology, head and neck diseases 129(5): 225-229. https://doi.org/10.1016/j.anorl.2011.10.011

37. McRackan TR, Abdellatif WM, Wanna GB, Rivas A, Gupta N, Dietrich MS, Haynes DS (2011) Evaluation of second look procedures for pediatric cholesteatomas. Otolaryngology--head and neck surgery : official journal of American Academy of Otolaryngology-Head and Neck Surgery 145(1):154160. https://doi.org/10.1177/0194599810396624

38. Osborn AJ, Papsin BC, James AL (2012) Clinical indications for canal walldown mastoidectomy in a pediatric population. Otolaryngology--head and neck surgery : official journal of American Academy of Otolaryngology-Head and Neck Surgery 147(2):316-322. https://doi.org/10.1177/ 0194599812445539

39. Vincenti V, Marra F, Bertoldi B, Tonni D, Saccardi MS, Bacciu S, Pasanisi E (2014) Acquired middle ear cholesteatoma in children with cleft palate: experience from 18 surgical cases. International journal of pediatric otorhinolaryngology 78(6):918-922. https://doi.org/10.1016/j.ijporl.2014.03. 007

40. Sergi B, Galli J, Battista M, De Corso E, Paludetti G (2014) Dealing with paediatric cholesteatoma: how we changed our management. Acta otorhinolaryngologica Italica : organo ufficiale della Societa italiana di otorinolaringologia e chirurgia cervico-facciale 34(2):138-143

41. Tos M (1983) Treatment of cholesteatoma in children. A long-term study of results. The American journal of otology 4(3):189-197

42. Glasscock ME, Dickins JR, Wiet R (1981) Cholesteatoma in children. The Laryngoscope 91(10):1743-1753

43. Bazzi K, Wong E, Jufas N, Patel N (2019) Diffusion-weighted magnetic resonance imaging in the detection of residual and recurrent cholesteatoma in children: a systematic review and meta-analysis. International journal of pediatric otorhinolaryngology 118:90-96. https://doi. org/10.1016/j.jporl.2018.12.031

44. Marchioni D, Soloperto D, Rubini A, Villari D, Genovese E, Artioli F, Presutti L (2015) Endoscopic exclusive transcanal approach to the tympanic cavity cholesteatoma in pediatric patients: our experience. International journal of pediatric otorhinolaryngology 79(3):316-322. https://doi.org/10.1016/j.ijporl. 2014.12.008
45. Rosenfeld RM, Moura RL, Bluestone CD (1992) Predictors of residualrecurrent cholesteatoma in children. Archives of otolaryngology--head \& neck surgery 118(4):384-391

46. Harner S, McDonald TJ (1992) Surgery of temporal bone air cell system: mastoid and petrosa. Otolaryngology Head and Neck Surgery, 2nd ed, Mosby Year Book, St Louis:2989Á

47. Austin DF (1989) Single-stage surgery for cholesteatoma: an actuarial analysis. The American journal of otology 10(6):419-425

48. Cody DT, McDonald TJ (1984) Mastoidectomy for acquired cholesteatoma: follow-up to 20 years. The Laryngoscope 94(8):1027-1030

49. Lingam RK, Khatri P, Hughes J, Singh A (2013) Apparent diffusion coefficients for detection of postoperative middle ear cholesteatoma on non-echo-planar diffusion-weighted images. Radiology 269(2):504-510. https://doi.org/10.1148/radiol.13130065

50. Muzaffar J, Metcalfe C, Colley S, Coulson C (2017) Diffusion-weighted magnetic resonance imaging for residual and recurrent cholesteatoma: a systematic review and meta-analysis. Clinical otolaryngology : official journal of ENT-UK ; official journal of Netherlands Society for Oto-RhinoLaryngology \& Cervico-Facial Surgery 42 (3):536-543. doi:https://doi.org/10. $1111 /$ coa.12762

\section{Publisher's Note}

Springer Nature remains neutral with regard to jurisdictional claims in published maps and institutional affiliations.

\section{Submit your manuscript to a SpringerOpen ${ }^{\circ}$ journal and benefit from:}

- Convenient online submission

- Rigorous peer review

- Open access: articles freely available online

- High visibility within the field

- Retaining the copyright to your article

Submit your next manuscript at $\boldsymbol{\nabla}$ springeropen.com 